\title{
Info Energy Medicine - Voice Sound for Diagnosis
}

\author{
Maria Kuman* \\ Holistic Research Institute, USA
}

${ }^{*}$ Corresponding author: Maria Kuman, $\mathrm{PhD}$, Holistic Research Institute, 1414

Barcelona Dr, Knoxville, TN 37923, USA, Tel: 865-309-4901; Email:

\section{Editorial}

Volume 2 Issue 3

Received Date: May 05, 2018

Published Date: May 11, 2018

holisticare1@gmail.com; Webpage: www.mariakuman.com

\section{Editorial}

The processes in our body are organized in space (tissue-specific organs) and in time. I started writing about the time organization and emphasize the importance of its consideration in 1993 [1]. The organization in time is handled by our nonlinear electromagnetic field (NEMF), which is a symphony of many different frequencies [2]. These frequencies sound in synch (or coherently) when we are healthy. Dr. Valerie Hunt showed that she could measure this coherence with her patented equipment. She found that healthy individuals had peaceful coherent vibrations with low amplitude.

Dr. Valerie Hunt found that unhealthy individuals had vibrations out of synch with amplitude changes of different magnitude. Here is our explanation of what exactly shifted the vibrations out of synch. Stress creates delays because the body need to stop whatever it was doing at the moment and mobilize for response to the stressor - fight or flight, adapt or resist. For the periodic reactions of the body, called biorhythms, these delays are called phase shifts, and they manifest as amplitude changes [3].

In healthy individuals, the frequencies of different organs in the bodies cohere to each other as the musical instruments in a orchestra playing harmonious music. This means that the waves of the different frequencies are inter-related and have a constant difference in phase. For this to happen, the waves must be related in a nonlinear way. Based on this, the author of this article claims that Dr. Hunt was actually measuring the human nonlinear electromagnetic field (NEMF).

Each organ is represented on the surface of the body by acupuncture meridian. The author of this article created a nonlinear mathematical model of one acupuncture meridian and theoretically predicted that waves must run along each acupuncture meridian [4]. A year later, the Hungarian scientist Dr. Eory experimentally confirmed the waves [5]. These waves are part of the human NEMF.

In Eastern Asia, pulse diagnosis has been used since ancient time until today for early detection of diseases [2]. The pulses of different organs are checked and compared. When an individual has a sick organ, the pulse diagnostician would detect amplitude changes in the frequency of this sick organs, which reflect the phase changes caused by stress. Dr. Valerie Hunt was not aware that the observed by her lack of wave synchronization in sick individuals was caused by stress.

When an individual is sick, the lack of synchrony in his body vibrations could also be detected in the voice frequencies of the individual, but such diagnosis requires high sensitivity. A sensitive individual should be able to diagnose all diseases: cancer, high blood pressure, etc. by voice analysis. Sharry Edwards was such high-sensitivity individual and she started Sound Health Institute for the purpose of voice diagnosis, but it all started like this.

She noticed that the voice of a friend with high blood pressure miss some frequency. Trying to explain this to him, she reproduced the missing frequency and the person collapsed on the floor because his blood pressure dropped too suddenly. She knew right away that she was onto something big. She could not only find, which frequency was missing for each disease, she could fix the problem or cure the disease by adding back the missing frequency. 


\section{Journal of Natural \& Ayurvedic Medicine}

Many years of hard work followed. Not only did she learn to diagnose many diseases based on voice analysis, she was able to computerize the whole process so that everybody else can do it. The lack of scientifically based theory has prevented the Bioacoustic field from being accepted as a possible medical modality regardless how impressive the results are. Here, we offer such explanation with the hope that this might help the acceptance of the Bioacoustic as an alternative method for diagnosis and cure.

The author of this article showed in a previous article that hypnosis by putting the conscious to sleep revealed that the subconscious contains a full record of everything we have seen, heard, smelled and emotionally experienced during our lifetime [6]. This requires a very compact subconscious record, which is possible only if the record is holographic, i.e. recorded through coherent laser-type of waves.

As shown in the same article, in the Subconscious not only are our visual images recorded holographically, the records of our hearing and smell are also holographic, and so are obviously the records of our voice [6]. If so, our voice should reflect the balance or lack of balance in the frequencies of our NEMF, which rules and regulates the functioning of the whole body. If so, by restoring the balance of frequencies, we can restore the health or cure the disease.

The future medicine will be vibrational medicine. It will be correcting the imbalances in our NEMF by adding the missing frequencies or phase shifting certain frequencies to restore the missing synchrony. The voice diagnosis and therapy are going to be one of the modalities of this vibrational medicine of the future, which can also be named Quantum Medicine or Info Energy Medicine because the cure is done with waves with certain frequency or information.

The Argentinian physiologist Hugo Zukareli patented a new system of recording holographic sound. It is a hologram of sound, not light. It is different from stereo sound and the author of this article is convinced it will have stronger physiological impact on the body [7].

We are reaching the threshold of our allopathic (cure with the opposite) medicine because the germs by multiplying fast adapt fast to the existing drugs, and we need to keep synthesizing newer and newer drugs to kill them. In the last 10 years, $40 \%$ of the pharmaceutical drugs were new. The new drugs are more powerful and have more side effects. Studies in Switzerland showed that more than $70 \%$ of the drugs have side effects.

And we already have new varieties of germs that none of our antibiotics can kill. Thus, in the fight with the germs, we seem to be loosing the battle. Even when we have a new strong drug that kills the newly modified germ, the side effects of the drug are so strong that together with the germ, they can kill the person. From here comes the necessity to look for new alternative ways of cure, such as vibrational or informational medicine.

As underlined in our article, our way of thinking plays a crucial role for our health and wellbeing [9]. Our measurements showed that positive (happy) thoughts make us healthier, while negative (sad) thought lead to a disease of the genetically weak organ. The Russian scientist Acad. Grabovoi outlined that to stay healthy, we need to avoid negative information or to find ways to get rid of the damage of this negative information before it has sank at physical level [8].

\section{References}

1. Kuman M (1993) What Everybody Needs to Know about Chronic Pain, Chronic Diseases and Cancer, Health and Happiness Books.

2. Kuman M (2017) International Journal of Integrated Medicine, 42: 97-112.

3. Kuman M (1985) Acta Oto-Rhyno-Laringologica Belgica 38: 523-529.

4. Kuman M (1983) $8^{\text {th }}$ World Congress on Acupuncture, Sofia, Bulgaria.

5. Eory A (1984) Acupuncture and Electro-Therapeutic Research 9: 217-223.

6. Kuman M, Holographic Ways of Seeing, Hearing, Smelling and Memorizing and How to Use Them for Diagnosis, Research in Medicine and Engineering Science (accepted).

7. Tihoplav V, Tohoplav T, Soznanie Vselenoi (2007) The Conscious of the Universe, In: Krilov Russia.

8. Tihoplav V, Tihoplav T, Garmonia Haosa (2003) The Harmony of the Chaos Russia.

9. Kuman M, Measuring the Role of Way of thinking in Life and Medicine, Research in Medicine and Engineering Science (accepted). 
